\title{
LA REFORMA DEL FEDERALISMO ALEMÁN. UNA VISIÓN GENERAL
}

\author{
MARÍA ÁNGELES MARTÍN VIDA \\ Universidad Johann-Wolfgang-Goethe, Frankfurt am Main ${ }^{1}$
}

\author{
SUMARIO \\ I. Introducción. \\ II. Necesidad y análisis de la reforma. \\ III. Reflexión final.
}

\section{INTRODUCCIÓN}

El Bundesrat alemán ha aprobado el día 7 de julio de 2006, con la mayoría necesaria de dos tercios ${ }^{2}$, la mayor reforma de la Ley Fundamental de Bonn (en adelante, GG) que se lleva a cabo desde que ésta entró en vigor en el año 1949, así como la modificación a través de la llamada "Ley de Acompañamiento a la Reforma del Federalismo" de otras leyes que se ven necesariamente afectadas por la reforma constitucional ${ }^{3}$. La "madre de todas las reformas", como se la ha dado en calificar, porque supondrá la introducción de cuarenta modificaciones en el texto de la Ley Fundamental, afecta fundamentalmente a la estructura del modelo federal alemán y al reparto de competencias entre la Federación y los Länder, y ya fue aprobada por el Bundestag, también por dos tercios, el pasado 30 de junió ${ }^{4}$.

1 La autora, Doctora en Derecho por la Universidad de Granada y LL. M. por la Universidad de Osnabrück, es Asistente científica en la Cátedra de Derecho Público y de la Seguridad Social del Prof. Inguer Ebsen.

262 votos a favor emitidos de los 69 posibles. Se necesitaban al menos 46 votos favorables. Sólo el Gobierno de coalición entre socialistas y comunistas de Mecklenburg-Vorpommern votó en contra, alegando que la reforma sólo beneficia a los Länder ricos, mientras que el Gobierno de coalición entre democristianos y socialistas de Schleswig-Holstein se abstuvo.

3 Las reformas introducidas y las leyes afectadas aparecen listadas en BT Drucksache 16/814, de 7 de marzo de 2006, pp. 3 y ss..

4428 diputados de la "Gran Coalición" de socialistas y democristianos votaron a favor de la reforma (era necesario el voto favorable de al menos 410 diputados, la "Gran Coalición" la componen 448); 162 parlamentarios votaron en contra; y tres se abstuvieron. 
La reforma, que ha entrado en vigor el 1 de septiembre de 2006 y cuya aprobación ya fracasó en diciembre de $2004^{5}$, persigue dotar de claridad al modelo de reparto de competencias entre Federación y Länder, aportando también claridad sobre quién es responsable políticamente de cada decisión, y agilizar el proceso legislativo a nivel federal. A partir de ahora, el número de leyes federales que necesitan contar con la aprobación del Bundesrat para ser aprobadas (las llamadas Zustimmungsgesetze) bajará del actual sesenta por ciento del total de leyes federales a menos del cuarenta por ciento (las previsiones más optimistas apuntan incluso a un veinticinco por ciento del total ${ }^{6}$ ).

La base de la reforma la han constituido los trabajos de la Comisión Conjunta del Bundestag y del Bundesrat para la Modernización del Orden Estatal Federal, constituida en octubre de 2003, y que preparó la fallida reforma del año 2004; el Acuerdo de Gobierno suscrito el 18 de noviembre de 2005 entre los partidos que integran la actual "Gran Coalición" de Gobierno en Alemania (CDU, CSU y SPD); y el Acuerdo alcanzado por la Canciller Federal y los Jefes de Gobierno de los Länder el 14 de diciembre de 2005. Muy probablemente después del verano de 2006 se emprenda la segunda parte de la reforma, la relativa a las relaciones financieras entre la Federación y los Länder, que se quiere aprobar también en esta legislatura (que en principio termina en 2009), pues parece poco probable poder sacarla adelante fuera de una gran coalición de Gobierno. La segunda parte de la reforma pretende, entre otras cuestiones que están aún por concretar, dotar a los Länder de nuevas competencias en materia de legislación impositiva e incorporar al texto constitucional algún tipo de freno al endeudamiento de los Länder, similar al que recoge el Derecho comunitario originario para los Estados miembros de la Unión Europea.

\section{NECESIDAD Y ANÁLISIS DE LA REFORMA}

\section{a) Objetivo y razón de ser de la reforma}

Lo que persigue fundamentalmente la reforma del federalismo alemán, llevada a buen puerto en su primera parte por la "Gran Coalición" de democristianos, democristianos bávaros y socialistas, es una mayor claridad en el reparto de competencias entre la Federación y los Länder, y una mayor transparencia y efectividad en el procedimiento legislativo a nivel federal. El objetivo

5 Sobre esta fallida reforma, véase el completo análisis de GUTIÉRREZ GUTIÉRREZ, Ignacio: "La fallida reforma del federalismo alemán". Teoría y Realidad Constitucional, núm. 16, 2005, pp. 377 y ss., a cuyas valoraciones me remito.

6 GEORGII, Harald y BORHANIAN, Sarab: Zustimmungsgesetze nach der Föderalismusreform. Wie hätte sich der Anteil der Zustimmungsgesetze verändert, wenn die vorgeschlagene Reform bereits 1998 in Kraft gewesen wäre? Berlín: Deutscher Bundestag, wissenschaftliche Dienste, 2006. 
último es el de "desliar la maraña que obstaculiza la democracia y la eficiencia en las relaciones entre la Federación y los Länder, delimitar responsabilidades de manera más clara, y reequilibrar los elementos federales de la solidaridad y la cooperación, de un lado, y la competencia de otro, con el fin de lograr un reforzamiento duradero de la capacidad de decisión y de actuación tanto de la Federación como de los Länder, así como de los entes locales» ${ }^{7}$. Hasta ahora, tal y como se explica en la fundamentación que acompaña al Proyecto de Ley para la Reforma de la Ley Fundamental de Bonn presentado por las fracciones de la CDU/CSU y del SPD ante el Bundestag alemán ${ }^{8}$, el marcado poder de los Länder para dar su consentimiento a través del Bundesrat ha conducido una y otra vez, en el ámbito de la legislación federal, como consecuencia de mayorías políticas diferentes en la Federación y en los Länder, a retrasos e, incluso, al bloqueo de proyectos de ley importantes, o a compromisos contradictorios en los que es difícil identificar a quién corresponde la respectiva responsabilidad política". Por otro lado, la Federación ha extendido sus competencias legislativas a ámbitos cada vez más amplios, por medio de reformas constitucionales, haciendo un uso exhaustivo de la legislación concurrente sobre las materias del artículo 74 GG, y mediante leyes marco que van más allá de lo que debería ser una ley marco, incluyendo normas directamente aplicables y regulando cuestiones de detalle.

Hay que recordar que el principio básico establecido en la Ley Fundamental de Bonn (art. 70 GG) es el de que la legislación es tarea de los Länder, salvo que en la propia Ley Fundamental se disponga otra cosa, y que la ejecución de las leyes, sean federales o sean de los Länder, corresponde, con carácter general, también a éstos. La Ley Fundamental atribuye expresamente a la Federación la competencia legislativa exclusiva (art. $71 \mathrm{GG}^{9}$ ) sobre las materias enumeradas en el artículo 73 GG, y la posibilidad de legislar sobre las materias, objeto de competencia legislativa concurrente, del artículo 74 GG, excluyendo con ello desde ese momento y en esa medida la competencia legislativa de los Länder sobre ellas (art. $72.1 \mathrm{GG}^{10}$ ).

Hasta ahora, la Federación ha extendido su competencia, haciendo uso de todos los posibles resquicios constitucionales, hasta extremos en principio impensados, en detrimento naturalmente de los Länder. Para compensar esta tendencia a la centralización de competencias se reforzó el papel de los Länder en el procedimiento legislativo federal, elevando notablemente la proporción

7 BT Drucksache 16/813, de 7 de marzo de 2006, p. 7 (la traducción corresponde siempre a la autora de la panorámica, salvo que expresamente se indique lo contrario).

8 BT Drucksache 16/813, de 7 de marzo de 2006, pp. 7 y ss.

9 Art. 71 GG: «Legislación exclusiva de la Federación: En el ámbito de la legislación exclusiva de la Federación tendrán los Länder competencia para legislar sólo si y en la medida en que una ley federal los autorice expresamente a ello".

10 Art. 72.1 GG: «Legislación concurrente: (1) En el ámbito de la legislación concurrente están los Länder autorizados para legislar mientras y en la medida en que la Federación no haya hecho uso de su competencia legislativa por medio de una ley". 
de las llamadas Zustimmungsgesetze ${ }^{11}$, leyes federales que no pueden ser aprobadas sin el consentimiento del Bundesrat, la Cámara de representación de los Länder ${ }^{12}$. El gran número de Zustimmungsgesetze ${ }^{13}$ provoca considerables retrasos en el procedimiento legislativo federal y, en la mayoría de las ocasiones por enfrentamientos políticos entre la Federación y los Länder ${ }^{14}$, acaba convirtiendo al Bundesrat en un "contraparlamento" ${ }^{15}$ que impide que importantes leyes salgan adelante. La Comisión de Mediación entre Bundestag y Bundesrat, que intenta adoptar textos legislativos que puedan ser aprobados contando con el apoyo tanto de una como de otra Cámara, ha multiplicado el número de sus intervenciones en el procedimiento legislativo pero no ha contribuido precisamente a simplificar y hacer más transparente el procedimiento parlamentario, entre otras cosas porque sus reuniones se celebran a puerta cerrada.

11 Por esta vía de la necesidad del voto favorable del Bundesrat para la aprobación de determinadas leyes, el peso político específico a la hora de influir en la regulación de ciertas materias que originariamente corresponderían los Länder se desplaza de los Parlamentos de éstos, que serían en principio quienes tendrían que legislar sobre estas cuestiones, a los Ejecutivos, que son los que representan los intereses de cada Land en el Bundesrat.

12 En general, el procedimiento legislativo para la aprobación de leyes federales en Alemania implica la participación de las dos Cámaras del Parlamento, Bundestag y Bundesrat. La participación del Bundesrat no tiene, sin embargo, un carácter decisivo idéntico en todos los casos: a) en el caso de las llamadas Einspruchsgesetze (que son, en principio, aunque sólo teóricamente, la mayoría), el Bundesrat tiene el derecho, una vez agotado el recurso a la Comisión mixta de Mediación (Vermittlungsausschuß), a oponerse a una ley que haya recibido la aprobación del Bundestag. El Bundestag puede, sin embargo, superar en una nueva votación la oposición del Bundesrat, aunque para ello se precisa el voto favorable de la mayoría absoluta de sus miembros (art. 77.4 GG). Superada, en su caso, la oposición del Bundesrat, la ley entra en vigor; b) en el caso de las llamadas Zustimmungsgesetze, por el contrario, la ley no puede entrar en vigor sin el voto favorable (expreso, además) del Bundesrat, que por otra parte no tiene un derecho de enmienda sobre la ley, sino a lo sumo el derecho a apelar a un procedimiento de mediación por parte de la Comisión Mixta, a la que también pueden recurrir el Bundestag y el Gobierno Federal. La ausencia de ese voto favorable del Bundesrat, una vez agotado, en su caso, el recurso a la Comisión de Mediación, es insuperable, de tal modo que si, pese a todo, la ley llegase a entrar en vigor, este defecto de forma determinaría su nulidad (BVerfGE 55, 274 (318)). No se puede identificar plenamente esa falta del voto favorable del Bundesrat con un veto absoluto, aunque tengan los mismos efectos, porque la exigencia de que el Bundesrat apruebe la ley para que ésta pueda entrar en vigor cuando se trata de una Zustimmungsgesetz es una exigencia positiva en todo caso, reclama una cooperación positiva del Bundesrat en el proceso de creación de esa ley, mientras que el veto tiene siempre una carácter esencialmente negativo, que impide concluir el proceso de creación de la ley.

13 Un resumen de las causas que explican el porqué de lo elevado de esta cifra en LÜCKE,

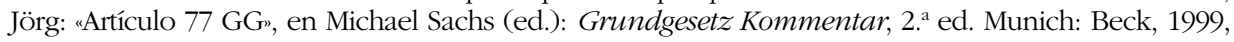
pp. 1495 y siguiente (números marginales 15 y ss).

14 El comentarista del semanario Die Zeit lo califica de estrategias maquiavélicas de los Lafontaines, Stoibers y Kochs", que habrían atribuido al Bundesrat «n papel de freno que los padres de la Constitución no habían previsto. Mediante la paralización de toda legislación reformista se debería ir allanando el camino de la oposición hacia la Cancillería. Y ha funcionado siempre. Con la pérdida de la mayoría en la Comisión de Mediación tras la derrota electoral del SPD en Renania del Norte-Westfalia en mayo de 2005 también Gerhard Schröder tuvo que tirar la toalla" (NAUMANN, Michael: "Die kalte Revolution — Der Machthunger reicher Bundesländer treibt die Föderalismusreform voran". Die Zeit, 2 de marzo de 2006).

15 ULRICH, Bernd: “Mehr Zentralismus!». Die Zeit, 22 de junio de 2006. 


\section{b) Contenido de la reforma}

\section{b.1. La reducción del número de Zustimmungsgesetze}

La reforma aspira, pues, por un lado, a reducir el número de Zustimmungsgesetze, de modo que la proporción de las mismas pase de suponer casi un sesenta por ciento del total de las leyes federales a representar aproximadamente sólo entre la cuarta parte y el cuarenta por ciento de las mismas ${ }^{16}$. Una de las reducciones más importantes se alcanzará gracias a la modificación del artículo $84.1 \mathrm{GG}^{17}$. Hasta ahora la Federación necesitaba contar con el con-

16 En general se podría decir que son Einspruchsgesetze todas aquellas leyes federales para cuya aprobación la Ley Fundamental no prevé como imprescindible el voto favorable del Bundesrat (esto es, todas aquéllas que no son Zustimmungsgesetze según la Ley Fundamental). Por su parte, y también con carácter general, podría decirse que son Zustimmungsgesetze aquellas leyes federales que penetran de manera directa e inmediata en la esfera de autonomía de los Länder o que alteran el ordenamiento federal básico, pero lo cierto es que lo son sólo en los supuestos concretos en los que la Ley Fundamental prevé expresamente que el voto favorable del Bundesrat resulte imprescindible para poder aprobar la ley: si la Ley Fundamental no contempla expresamente un determinado supuesto como necesitado del voto favorable del Bundesrat, por mucho que haya injerencia en la esfera de autonomía de los Länder, estaremos ante una Einspruchsgesetz. La Ley Fundamental contenía hasta ahora en total cuarenta cláusulas relativas a la necesidad del voto favorable del Bundesrat para la aprobación de leyes federales. Veintiocho de esas cláusulas no figuraban en la redacción inicial de la Ley Fundamental, sino que fueron siendo incorporadas a ella posteriormente. Naturalmente, no siempre es fácil resolver la importante cuestión, no sólo por su relevancia política, sino también por su trascendencia práctica, de si un proyecto de ley pertenece materialmente a la categoría de las Einspruchsgesetze o de las Zustimmungsgesetze, hasta el punto de que muchas veces la decisión acaba correspondiendo al Tribunal Constitucional. Téngase en cuenta, además, que, según la jurisprudencia del Tribunal Constitucional alemán (véanse, entre otras, BVerfGE 8, 274 (294); 24, 184 (195); 34, 9 (28); 37, 363 (381); 39, 1 (35); 48, 127 (178); 55, 274 (319); y 73, 363 (382)), el término "ley necesitada del voto favorable del Bundesrat" hay que interpretarlo, no en el sentido de "norma individualizada", sino en el sentido de "unidad desde el punto de vista técnico-legislativo", de tal modo que la exigencia del voto favorable del Bundesrat en el caso de las Zustimmungsgesetze alcanza al conjunto de la ley cuya elaboración esté siendo tramitada en el Parlamento, como un todo (tesis de la unidad), incluso aunque sólo uno de sus preceptos se refiera al establecimiento de las autoridades administrativas de los Länder o a la regulación del procedimiento administrativo en ese ámbito o al reparto de finanzas entre la Federación y los Länder. Esta interpretación se explica por motivos eminentemente prácticos y de funcionalidad del procedimiento legislativo, porque en cualquier caso los intereses de los Länder quedarían suficientemente protegidos si la exigencia del voto favorable del Bundesrat alcanzase sólo a aquellos preceptos que suponen una injerencia considerable de la Federación en el ámbito de autonomía organizativa de los Länder. En cualquier caso, al menos teóricamente, desde la perspectiva del principio de lealtad constitucional y desde la corresponsabilidad del Bundesrat en la tarea de legislar a nivel federal, la negativa de la Cámara de representación territorial a votar a favor de una ley que necesita de su aprobación para poder entrar en vigor habría de basarse en su disconformidad con alguno de los preceptos de la misma a los que efectivamente alcanza la necesidad de su acuerdo, no en su disconformidad con aquella parte del contenido de la ley que no lo necesita. Sin embargo, en la medida en que el Bundesrat no está obligado a motivar las razones que lo llevan a oponerse a una ley o a no aprobarla, esta circunstancia es difícilmente controlable.

17 Sobre la interpretación que hasta ahora se había dado a este precepto, puede verse más ampliamente MARTíN VIDA, María Ángeles: “Las Zustimmungsgesetze en la jurisprudencia del Tribunal Constitucional Federal Alemán". Revista de la Facultad de Derecho de la Universidad de 
sentimiento del Bundesrat para poder aprobar leyes federales relativas al establecimiento de los órganos administrativos de los Länder, al procedimiento administrativo, a la aprobación de tasas administrativas, o a los requisitos de notificación de los actos administrativos, porque la ejecución de leyes federales está, con carácter general, en manos de los Länder, como se dijo anteriormente. La regulación de su propia Administración es, originariamente y de forma evidente, competencia normativa de los Länder, según se deduce de la lectura del artículo 84.1 GG. La Ley Fundamental, sin embargo, posibilitaba, a través básicamente de ese mismo precepto, que en ese ámbito de clara competencia de los Länder la Federación pudiese llegar a regular el establecimiento de instituciones administrativas o el procedimiento administrativo aplicable cuando los Länder ejecutan leyes federales como tarea propia $^{18}$, en lo que constituiría una injerencia de la Federación difícilmente soportable de no ser por el decisivo papel que, en defensa de los intereses de los Länder, se atribuía a la Cámara de representación territorial. Presupuesto, de todos modos, para que el legislador federal pueda elaborar una ley en esta materia era, según el propio artículo 84.1 GG, que se tratase de ejecutar leyes federales en sentido formal cuya ejecución correspondiese a los Länder como tarea propia ${ }^{19}$; por ello resultaba obligatorio para la Federación elaborar leyes que diesen a los Länder margen para su ejecución.

A partir de ahora, la Federación podrá regular esta materia, que era la que más Zustimmungsgesetze había generado, sin contar con el consentimiento del Bundesrat. Ahora bien, a los Länder se les permite a partir de ahora adoptar en este ámbito normas con rango de ley que se aparten de lo regulado en la ley federal. Sólo en supuestos excepcionales, que necesitarán de nuevo contrar con el consentimiento del Bundesrat, podrá regular la Federación el procedimiento administrativo sin que los Länder puedan aprobar normas que se aparten de la regulación federal.

Por otro lado, la aprobación de leyes federales que conlleven consecuencias financieras considerables para los Länder (no sólo en forma de pagos en metálico a terceros, como hasta ahora, sino también en forma de prestaciones materiales) necesitará contar en cualquier caso con el consentimiento del Bundesrat (art. 104a.3 y 3a GG).

Granada, núm. 6, 2003, pp. 331 y ss., y las referencias bibliográficas y jurisprudenciales que en ese trabajo se citan.

18 La ejecución de leyes federales por los Länder como tarea propia es la regla general (art. $83 \mathrm{GG}$ ).

19 En relación a la "regulación del procedimiento administrativo en el ámbito de los Länder", la exigencia del voto favorable del Bundesrat alcanzaría también, según la opinión mayoritaria, pese a no estar expresamente contemplado en el artículo 85.1 GG, a aquellas leyes federales que regulan el procedimiento administrativo en el marco de tareas administrativas federales cuyo ejercicio ha encargado la Federación a los Länder (Bundesauftragsverwaltung), y no sólo a las que lo regulan en el contexto de la Administración propia de los Länder. El Tribunal Constitucional Federal Alemán, en cualquier caso, todavía no se ha pronunciado expresamente a este respecto, aunque así parece deducirse de su sentencia BVerfGE 26, 338 (385). 


\section{b.2. Reducción de las competencias legislativas de la Federación}

La reducción del número de Zustimmungsgesetze es la vía utilizada para reducir la influencia de los Länder en el procedimiento legislativo federal. El otro aspecto de la reforma se centra en disminuir, en favor de los Länder, las competencias legislativas de la Federación. Ello se hace por varias vías: supresión de la legislación marco, reordenación del catálogo de materias sujetas a legislación concurrente, reducción del ámbito de aplicación de la "cláusula de imprescindibilidad" (Erforderlichkeitsklausel) del artículo 72.2 GG, e introducción de la posibilidad de que los Länder puedan en numerosos ámbitos apartarse mediante normas con rango de ley, de la legislación federal ${ }^{20}$.

\section{i. Reordenación de la competencia legislativa concurrente}

La competencia legislativa concurrente sobre las materias del artículo 74.1 GG se mantiene. La regla sigue siendo que los Länder sólo son competentes para regular las materias a las que se refiere el artículo 74.1 GG (legislación concurrente) mientras y en la medida en que la Federación no las haya regulado ella misma. Para que la Federación pudiese legislar sobre tales materias era, hasta ahora, necesario en todo caso que una regulación a nivel federal fuese imprescindible para garantizar el establecimiento de una cierta igualdad en todo el territorio federal o para asegurar la unidad económica y jurídica en interés del conjunto del Estado, según dispone el artículo 72.2 GG (la llamada "cláusula de imprescindibilidad") desde su reforma en 1994. La interpretación de esta exigencia ha sido desde el año 1994 una de las cuestiones más debatidas en el Derecho Constitucional alemán ${ }^{21}$. La reforma mantiene la legislación concurrente sobre determinadas materias, pero limita la

20 Como dice Ignacio GUTIÉRREZ, «se da por supuesto que, en la mayor parte de los casos, sólo algunos Länder se apartarían de la legislación federal, y sólo para regular aspectos singulares. Cabría incluso suponer que, si una de esas normas evidencia su idoneidad, sería asumida por los demás Länder o por la propia ley federal, recuperándose así la unidad de regulación. También se preservaría de este modo el interés de ciertos Länder por no verse obligados a regular por sí mismos todos estos aspectos" (GUTIÉRREZ GUTIÉRREZ, I., op. cit., p. 390). Para evitar el problema que sin duda va a suponer a los operadores jurídicos saber en cada momento qué normativa se aplica, los impulsores de la reforma pretenden conseguir que la Federación y los Länder se comprometan a garantizar que en determinados sistemas de documentación (se está pensando sobre todo en la prestigiosa base de datos Juris) aparezcan reflejadas de manera conjunta las normas federales de las que se aparte la ley de algún Land y las leyes de cada Land que se apartan del Derecho federal, al margen de que las normas en cuestión sean publicadas por separado en los respectivos Boletines Oficiales (BT Drucksache 16/2052, de 28 de junio de 2006, p. 8).

21 Si efectivamente concurren las circunstancias que, de acuerdo con el artículo 72.2 GG, hacen imprescindible la normativa federal es algo que al final suele acabar decidiendo el Tribunal Constitucional Federal, el cual en los últimos años ha adoptado una línea muy favorable a la posición de los Länder, tendencia para muchos ineficiente y políticamente insatisfactoria. 
aplicación de la "cláusula de imprescindibilidad" a sólo algunas de ellas ${ }^{22}$ (el derecho de residencia y establecimiento de los extranjeros en territorio alemán, la asistencia social, el tráfico rodado, la responsabilidad del Estado, la reproducción asistida de seres humanos, etc.). Para el resto de las materias del apartado 1 del artículo 74 GG se parte de la base de que la Federación y los Länder están de acuerdo en que concurren las exigencias que hacen imprescindible una regulación federal de la materia en cuestión, pero se da a los Länder la posibilidad de apartarse de las normas que pueda dictar la Federación sobre tales materias, aunque, naturalmente, tendrán que respetar los preceptos constitucionales y comunitarios y los compromisos internacionales asumidos por el Estado alemán. El último inciso del artículo 72.3 GG incluye ahora una referencia expresa a la vigencia de la regla lex posterior derogat priori para regular las relaciones entre el Derecho federal y el Derecho de los Länder en este punto («en los ámbitos enumerados en el primer inciso tendrá preferencia en la relación entre Derecho federal y Derecho de los Länder la que cada vez sea ley posterior"). La idea es, por tanto, no excluir a la Federación, como titular de la competencia legislativa concurrente, de la posibilidad de aprobar en el futuro nuevas leyes en la materia de que se trate. El Derecho federal más reciente tendría entonces vigencia en el conjunto del territorio de la Federación y desplazaría al Derecho que los Länder hubiesen podido aprobar para apartarse de la inicial normativa federal. Los Länder a su vez podrán volver a aprobar leyes que se aparten de la nueva normativa federal y así sucesivamente, en lo que se ha dado en denominar el "efecto ping-pong".

\section{ii. Supresión de la legislación marco}

Se suprime la legislación marco (Rabmengesetzgebung), mediante la cual la Federación podía regular hasta ahora, siempre que se diesen los requisitos del apartado 2 del artículo 72 GG, los principios básicos de la enseñanza superior o de la función pública, entre otras materias (art. 75 GG), preceptos marco que luego los Länder se encargaban de concretar mediante leyes propias. La Federación había utilizado la legislación marco para aprobar leyes que iban más allá de los límites previstos para la legislación marco, lo cual forzaba repetidamente a correcciones por parte del Tribunal Constitucional Federal alemán. Además, según se deduce de la fundamentación de la propia Ley de Reforma Constitucional, esta técnica se había mostrado particularmente ineficaz cuando se trataba de transponer el Derecho Comunitario en el Derecho interno ${ }^{23}$. Las materias sobre las que hasta ahora la Federación podía dictar leyes marco de

22 Sólo once de los treinta y tres números del artículo 74.1 GG quedan sujetos a la "cláusula de imprescindibilidad".

23 BT Drucksache 16/813, de 7 de marzo de 2006, p. 8. 
acuerdo con el artículo 75 GG pasan a repartirse entre la competencia legislativa de la Federación y la de los Länder ${ }^{24}$.

\section{iii. Nuevo reparto de competencias entre la Federación y los Länder}

Se produce, pues, una reordenación de las competencias sobre ciertas materias:

- en materia de Derecho funcionarial, si hasta ahora le correspondía a la Federación regular mediante una ley marco los aspectos generales de la función pública de los Länder y entes locales, ahora la regulación de las retribuciones, pensiones y ascensos de sus funcionarios y de los funcionarios de sus entes locales, pasa a ser asunto de cada Land $^{25}$. La Federación conserva la competencia legislativa concurrente para regular (mediante una ley que necesitará el consentimiento del Bundesrat) los restantes derechos y deberes estatutarios de los funcionarios y jueces de los Länder y entes locales. Se modifica el apartado 5 del artículo 33 GG para que la garantía institucional en él contenida, que se mantiene, no siga siendo interpretada como una petrificación del status quo, sino que sea posible desarrollar en adelante por el legislador competente los principios tradicionales de la función pública.

- la protección del patrimonio cultural para evitar su expatriación (nuevo art. 73.1.5a GG) y las materias "empadronamiento y expedición de documentos de identidad" (nuevo art. 73.1.3 GG), que antes eran objeto de la legislación marco, pasan a ser competencia legislativa exclusiva de la Federación ${ }^{26}$.

- la regulación del derecho de prensa pasa a ser competencia exclusiva de los Länder.

- el resto de las materias que antes eran objeto de legislación marco (todas las relacionadas con el medio ambiente ${ }^{27}$, como la protección de la

24 La legislación marco vigente y las leyes de los Länder que la hayan desarrollado hasta ahora siguen estando en vigor (art. 125b.1 GG). Desde la entrada en vigor la reforma constitucional, la Federación no podrá dictar leyes marco. Los Länder podrán modificar sus leyes de desarrollo respetando el Derecho federal vigente.

25 Lo cual ha generado en los Länder más pobres el temor a una posible competencia entre Länder que pueda determinar el desplazamiento de sus funcionarios hacia Länder donde estén mejor pagados.

26 Las normas de los Länder que estén vigentes en estos ámbitos se mantienen en principio en vigor e irán siendo sustituidas por Derecho federal (art. 125a.3 GG).

27 La intención, tal como figura en el Acuerdo de Coalición, es que la Federación apruebe en el futuro un auténtico Código de Derecho Medioambiental que refuerce, mediante una simplificación y unificación de los procedimientos de concesión de licencias, el atractivo de Alemania como lugar de establecimiento de empresas. Qué valor tendrá ese Código y en qué quedarán los objetivos que con él se persiguen cuando los Länder empiecen a apartarse de las normas en él contenidas es algo que los críticos de la reforma ya se están planteando (SCHMIDT, T.E., loc. cit.). 
naturaleza, el cuidado del paisaje y los recursos hidráulicos, así como el acceso a las Universidades y títulos universitarios, y otras) pasan a ser objeto de legislación concurrente no sujeta a la "cláusula de imprescindibilidad" del artículo $72.2 \mathrm{GG}^{28}$, si bien se da a los Länder la posibilidad de dictar leyes que se aparten de los que pueda regular la Federación en estas materias (salvo en aspectos nucleares de la materia en cuestión enumerados en la propia Ley Fundamental, como, por ejemplo, la protección del entorno marino). Para facilitar la tarea legislativa de los Länder que opten por apartarse de la regulación federal se dispone que las leyes federales en estas materias entrarán en vigor al menos seis meses después de su promulgación, salvo que se haya dispuesto otra cosa contando con el consentimiento del Bundesrat (nuevo art. 72.3 GG).

- numerosas materias que antes eran objeto de legislación concurrente (art. 74.1 GG) pasan a ser competencia exclusiva de los Länder, entre ellas, por citar sólo las más importantes o las que más discusión han generado, la ejecución de las penas y de la prisión provisional; el derecho de reunión; el horario de cierre de los comercios; ferias, exposiciones y mercados; el ruido generado por instalaciones deportivas y de ocio con un fin social; y la enseñanza superior y universitaria (salvo el acceso a la Universidad y la regulación de títulos universitarios, que siguen siendo objeto de legislación concurrente, aunque se permite a los Länder dictar leyes que se aparten de la regulación federal) ${ }^{29}$. A la Federación le corresponde ahora en exclusiva la competencia para legislar en materia de armas y materiales explosivos (nuevo art. 73.1.12 GG), energía atómica (nuevo art. 73.1.14 GG) y la asistencia a los damnificados por la guerra (nuevo art. 73.1.13 GG).

- otras materias objeto de legislación concurrente (sanidad, alimentación, tráfico rodado, medio ambiente, reproducción humana asistida, entre otras) ven precisado su contenido para evitar lagunas en la regulación.

- se crea un nuevo título competencial, que se atribuye en exclusiva a la Federación, en materia de defensa preventiva frente al terrorismo inter-

28 La idea es, según se explica en el documento que acompaña al proyecto de ley de reforma presentado ante el Bundestag (BT Drucksache 16/813, de 7 de marzo de 2006, p. 11), que la Federación, que antes sólo podía regular los preceptos marco de estas materias relacionadas con el medio ambiente y la educación superior, pueda ahora regular de forma exhaustiva las mismas para facilitar con ello una transposición unitaria en el Derecho alemán del Derecho de la Unión Europea sobre estos temas. No obstante, el Comisario de Medio Ambiente de la Unión Europea ha manifestado ya su temor ante las dificultades que Alemania va a tener, con las reformas introducidas, para transponer las directivas en materia de medio ambiente (SCHMIDT, T.E., loc. cit.).

29 Las leyes federales vigentes en estas materias, entre ellas la Ley Marco de Enseñanza Superior (Hochschulrabmengesetz), mantienen en principio su vigencia, pero no podrán de ahora en adelante ser modificadas por la Federación, sino que irán siendo sustituidas por la regulación que dicten los Länder (art. 125a.1 GG). 
nacional cuando el peligro afecte a más de un Land, si bien para su regulación se precisa una ley federal (o que se complemente la ley federal vigente que regula la Agencia Federal contra el Crimen - Bundeskriminalamt-) que cuente con el consentimiento del Bundesrat (nuevo art. 73.1.9a GG).

- la enseñanza a nivel escolar, que era el asunto que hizo fracasar el intento de reforma de 2004, pasa a quedar en manos en exclusiva de los Länder, mientras que la Federación conserva su competencia en materia de formación profesional fuera de las escuelas.

\section{b.3. Otros aspectos importantes de la reforma}

Son fundamentalmente tres:

1. Se pretende reforzar la capacidad de maniobra en Europa mediante una nueva regulación de la representación del Estado alemán ante la Unión Europea. La representación del Estado la asumirá con carácter obligatorio un representante de los Länder elegido por el Bundesrat sólo cuando el debate verse sobre educación no superior, cultura y radiodifusión (art. 23.6 GG). Para el resto de las materias, la representación la asumirá un miembro del Gobierno federal.

2. Se garantiza una cierta protección financiera para los entes locales al prohibirse de ahora en adelante (art. 84.1 in fine y art. 85.1 in fine GG) que la Federación les pueda asignar directamente tareas (y, con ello, gastos) mediante ley. Esa atribución de tareas a los entes locales podrá llevarse a cabo a partir de ahora sólo por vía del Derecho de los Länder. Durante un período transitorio rige la regla del artículo 125a.1 GG, según la cual el Derecho federal ya existente seguirá vigente en este punto, pero puede ser sustituido a partir de ahora por Derecho de los Länder.

3. Se incluye una referencia en la Ley Fundamental de Bonn (nuevo art. 22.1 GG) a la capitalidad de Berlín, y se dice expresamente que la representación del conjunto del Estado alemán en la capital corresponderá a la Federación.

\section{b.4. Los aspectos financieros de la reforma}

En lo que a la "Constitución financiera" y a las relaciones entre la Federación y los Länder en este terreno se refiere, se introducen sólo algunas modificaciones puntuales (algunas de ellas muy importantes) en la Ley Fundamental de Bonn. La idea es empezar a discutir después del verano de 2006 un gran bloque de reformas financieras y tributarias, en lo que supondrá la segunda parte de la reforma del federalismo. 
Las reformas introducidas ahora suponen un refuerzo de la autonomía tributaria de los Länder ${ }^{30}$ (art. 105.2a GG, de modo que los Länder podrán ahora fijar la tarifa del Impuesto de Adquisición de Terrenos, cuyos ingresos ya les correspondían), y la regulación expresa del reparto de responsabilidades financieras entre la Federación y los Länder en los supuestos de incumplimiento o violación por el Estado alemán de obligaciones internacionales o comunitarias. La regla general que se aplica, por ejemplo, en el caso de que la Unión Europea imponga una sanción pecuniaria al Estado alemán por no transposición de Directivas comunitarias o el Tribunal Europeo de Derechos Humanos lo condene por violación del Convenio Europeo de Derechos Humanos o de sus Protocolos Adicionales, es que la responsabilidad a nivel interno recaerá sobre el ente que haya vulnerado la obligación internacional o comunitaria de que se trate, es decir, que habrá que atender al principio de reparto interno de competencias y tareas para determinar quién asume a nivel interno las consecuencias económicas de la violación (nuevo art. 104a.6 GG). La Ley Fundamental se remite a una ley federal, que ha de ser aprobada con el consentimiento del Bundesrat, para regular aspectos más puntuales de esta cuestión ${ }^{31}$. En caso de incumplimiento de las obligaciones derivadas del Pacto de Estabilidad Europeo, sobre todo por un excesivo endeudamiento público, que es un tema candente en la actualidad y que parece inevitable que acabará yendo acompañado de sanciones económicas para el Estado alemán, se incluye una regla especial (el llamado "Pacto Nacional de Estabilidad") en el nuevo artículo 109.5 GG, según la cual la Federación tendrá que responder en un sesenta y cinco por ciento de las sanciones que puedan imponerse por ese incumplimiento, mientras que los Länder responderán del otro treinta y cinco por ciento ${ }^{32}$.

Una de las cuestiones más importantes que tendrá que afrontar a fondo la segunda parte de la reforma del federalismo alemán es la de la financiación mixta, que se considera ineficiente, como ha manifestado el propio Tribunal Federal de Cuentas al informar el proyecto de reforma del federalismo. Se suprimen ahora las ayudas financieras de la Federación al transporte público o a la construcción de viviendas a nivel local (art. 125c.2 GG). Se suprime también la

30 Cualquier importante reforma impositiva que decida llevar a cabo la Federación sigue necesitando el consentimiento de los Länder a través del Bundesrat.

31 Esa ley (Lastentragunsgesetz) ha sido aprobada como parte de la Ley de Acompañamiento a la Ley de Reforma Constitucional de la que se ocupa este trabajo. Más detalles sobre las líneas maestras de la misma en BT Drucksache 16/2052, de 28 de junio de 2006, pp 5-6.

32 A su vez, del treinta y cinco por ciento de la cantidad que tengan que abonar los Länder responderán cada uno de ellos en función de su población, mientras que el resto lo abonarán cada uno en función del grado de responsabilidad que hayan tenido en el incumplimiento de las obligaciones derivadas del Pacto de Estabilidad Europeo. La llamada Ley de Reparto del Pago de Sanciones (Sanktionenzablungs-Aufteilungsgesetz), a la que la Ley Fundamental se remite para regular esta cuestión con más detalle, ha sido aprobada como parte de la Ley de Acompañamiento a la Ley de Reforma Constitucional objeto de este trabajo. Los Länder más pobres advierten que la aplicación de esta norma de reparto de sanciones los conducirá a la situación de emergencia presupuestaria. 
financiación mixta para la construcción de Universidades y Hospitales Clínicos Universitarios (antiguo art. 91a.1 GG). Se mantienen, sin embargo, las ayudas federales dedicadas a la mejora de la estructura económica regional y de las estructuras agrarias y a la protección de las costas (art. 91a.1.2 y 3 GG), y se mantiene la cofinanciación ${ }^{34}$ para estimular el desarrollo de proyectos de investigación científica de importancia supraregional en o fuera de las Universidades y Centros de Enseñanza Superior (art. 91b GG).

Asimismo, la Federación tiene que seguir garantizando ayudas financieras para inversiones importantes de los Ländery de los entes locales cuando ello sea necesario para evitar una alteración del conjunto de la economía, para equilibrar el diferente potencial económico de los diversos territorios de la Federación o para estimular el crecimiento económico. Ahora bien, en el nuevo artículo 104b GG se establece que la Federación sólo ha de garantizar esas ayudas cuando ella misma tenga algún tipo de competencia legislativa sobre la materia de que se trate, no así cuando la competencia legislativa corresponda en exclusiva a los Länder ${ }^{35}$. La idea que hay detrás de esta "prohibición de cooperación" (Roman Herzog, antiguo Presidente de la República Federal de Alemania, dice que mejor habría que llamarla "prohibición de corrupción") es evitar que la Federación financie determinadas tareas que corresponden en exclusiva a los Länder "comprando" de ese modo el apoyo de éstos en el Bundesrat.

\section{REFLEXIÓN FINAL}

Las cuestiones más polémicas en el marco del sistema federal alemán no han sido, sin embargo, objeto de esta reforma: no se ha reordenado la configuración territorial de los Länder alemanes (hay voces que se pronuncian a favor de una reducción en el número de Länder mediante la fusión de los Länder más pequeños y más pobres, que serán previsiblemente, y la espera de lo que se decida después del verano, los que más salgan perdiendo con las reformas), ni se han alterado en lo sustancial las relaciones financieras entre la Federación y los Länder, reforma que se deja para una segunda parte, sobre la que se empezará a negociar en otoño de 2006, y que muchos dudan que acabe saliendo adelante, con lo que la reforma actualmente aprobada quedaría incompleta y tendría serias dificultades de operatividad.

Sobre si lo que hay detrás de la sin o duda necesaria reforma llevada a cabo son motivos tan loables como los que se afirman (incrementar la transparencia y la atribución de responsabilidades políticas en los procesos de toma

33 También es posible que se acuerde entre la Federación y los Länder que sea la Federación la única que financie el proyecto de que se trate (BT Drucksache 16/813, de 7 de marzo de 2006, p. 16).

34 De esta "prohibición de cooperación", como se la denomina, se excluye en cualquier caso expresamente, como se ha visto, la cofinanciación de proyectos de investigación científica (art. $91 \mathrm{~b}$ GG). 
de decisiones, refuerzo del papel de los Parlamentos de los Länder, agilización del procedimiento legislativo federal) o si lo que en el fondo se oculta detrás de todo ello es un afán de los Presidentes de algunos Länder, los más fuertes económicamente y los que más van a salir ganando con la implantación de un "federalismo competitivo", de reforzar el poder político dentro de su territorio aun perdiendo influencia en la política federal, es algo sobre lo que se puede libremente especular. Los Länder más pobres ${ }^{36}$ no verán reforzado el papel de sus Parlamentos, ni las elecciones en esos Länder dejarán de ser elecciones nacionales disfrazadas, porque, al no disponer de medios suficientes para desarrollar sus propias políticas, esos Länder no podrán apartarse del Derecho federal y no podrán entrar en el juego del "federalismos competitivo", con lo cual los argumentos de que a partir de ahora los Parlamentos de los Ländervan a tener de verdad algo que regular o de que las responsabilidades de la Federación y de los Länder están a partir de ahora perfectamente delimitadas, se les aplican a ellos con muchos matices. Si con todo ello Alemania va a ganar fuerza en una economía globalizada parece, en principio, dudoso, aunque habrá que esperar a ver si los políticos alemanes son capaces, antes del final de la "Gran Coalición" de Gobierno, de sacar adelante y en qué terminos la segunda parte de la reforma, la que se refiere a las relaciones financieras entre la Federación y los Länder.

ABSTRACT. The German Parliament has just passed the largest amendment of the Basic Law since its coming into effect in 1949. The "mother of all revisions", which has entered into force the 1st September 2006, seeks on the one hand to clarify the system of apportionment of competences between the Federation and the Länder by limiting, to the advantage of the Länder, the number of fields over which the Federation has the power to legislate, and by setting out who is politically responsible for each decision. On the other hand, the revision seeks to speed up the legislative procedure at federal level by reducing the number of federal bills requiring upper house approval (Zustimmungsgesetze). The second part of the revision, concerning the financial relations between the Federation and the Länder, will most probably be undertaken in Autumn 2006. The intention is to adopt it during this legislative period, while the current Government coalition (the so called "Grand Coalition") still holds a wide parliamentary majority.

35 Según el Presidente de Baviera y jefe de la CSU, Edmund Stoiber, sólo cinco de los dieciséis Länder que componen la Federación son financieramente capaces de actuar por sí mismos. El resto dependen de las ayudas financieras de la Federación. 